\title{
Genitourinary Hemorrhagic Complications and Malignancies in Patients Receiving Anticoagulation Therapy
}

\author{
Eitaro Kodani, MD, PhD
}

$\mathbf{H}$ emorrhagic complications are a perpetual problem in any patient receiving anticoagulation therapy, not only in those with atrial fibrillation (AF). Net clinical benefit of anticoagulation therapy can be obtained when the incidence of hemorrhagic events is less than that of thromboembolism. ${ }^{1}$ Therefore, physicians have always considered the balance of risk (i.e., hemorrhagic complications) and benefit (i.e., prevention of thromboembolism) to achieve positive results of anticoagulation therapy. Although hematuria is a common and important hemorrhagic complication, along with intracranial hemorrhage and gastrointestinal bleeding, there is little information about genitourinary tract bleeding during anticoagulation therapy in preceding studies.

In this issue of the Journal, Yu et $\mathrm{al}^{2}$ focus on hematuria and genitourinary complications in patients with AF receiving oral anticoagulation therapy (OAT). The authors clearly demonstrate that the frequency of hematuria and its grade are higher in patients with OAT than in those not on OAT. The prevalence of bladder cancer was higher in patients with OAT, even in the propensity score-matched population, and the risk of bladder cancer was associated with urine red blood cell (RBC) grading. The odds ratio for genitourinary cancers in patients with urine $\mathrm{RBC}$ grade $3+$ and gross hematuria was significantly higher compared with patients with urine $\mathrm{RBC}$ grade $1+\left(\right.$ Figure 1A). ${ }^{2}$

\section{Considerations for Hematuria}

Several possibilities for the cause of hematuria during anticoagulation therapy should be considered, as well as gastrointestinal bleeding. First, preexisting benign organic disorders or malignancies as the source of bleeding are actualized by anticoagulation therapy. Most hemorrhagic complications in the genitourinary and gastrointestinal tracts may correspond to this hypothesis. The authors also state that being on OAT can detect preexisting occult genitourinary cancer earlier, especially bladder cancer. ${ }^{2}$ Indeed, the pathological grade of bladder cancer detected in patients with OAT was lower than that in those who were not, indicating that OAT had helped to detect the cancer earlier. ${ }^{2}$

Second, another consideration is whether an anticoagulant itself influences the incidence of genitourinary cancer. A few years ago, Lewis et al reported from the Kaiser Permanente Northern California diabetes registry that the

\section{Article p 158}

long-term use ( $>2$ years) of pioglitazone, an oral hypoglycemic agent for diabetes mellitus, increased the risk of bladder cancer among diabetic patients (hazard ratio, 1.4; 95\% confidence interval, 1.0-2.0). ${ }^{3}$ Subsequent pooled multipopulation analysis revealed that the cumulative use of pioglitazone was not associated with the incidence of bladder cancer. ${ }^{4,5}$ However, the impact of the first result was larger than the beneficial effect of pioglitazone and the use of this drug has decreased worldwide, despite it being reported to reduce the risk of macrovascular events such as nonfatal myocardial infarction, stroke, and all-cause death in patients with type 2 diabetes. ${ }^{6}$ Therefore, the mitogenic potency and oncogenicity of drugs should be taken into account, especially in patients who are undergoing longterm drug therapy. Fortunately, there has been no evidence that warfarin itself increases the incidence of renal or bladder cancer. Conversely, an anticancer effect of warfarin can be found in some reports, in which the long-term use of warfarin was associated with a lower incidence of prostate cancer. $^{7-9}$ These findings support the first hypothesis.

Age is a strong risk factor for the incidence of cancer. Indeed, the odds ratio for genitourinary cancers in patients

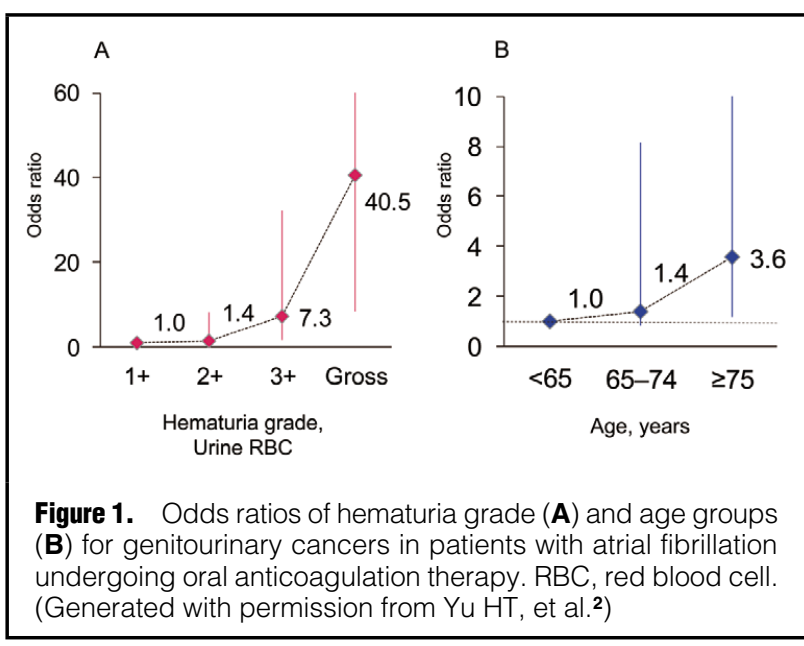

The opinions expressed in this article are not necessarily those of the editors or of the Japanese Circulation Society.

Received November 17, 2016; accepted November 17, 2016; released online December 14, 2016

Department of Internal Medicine and Cardiology, Nippon Medical School, Tama-Nagayama Hospital, Tokyo, Japan

Mailing address: Eitaro Kodani, MD, PhD, Department of Internal Medicine and Cardiology, Nippon Medical School, Tama-

Nagayama Hospital, 1-7-1 Nagayama, Tama, Tokyo 206-8512, Japan. E-mail: kodani@nms.ac.jp

ISSN-1346-9843 All rights are reserved to the Japanese Circulation Society. For permissions, please e-mail: cj@j-circ.or.jp 


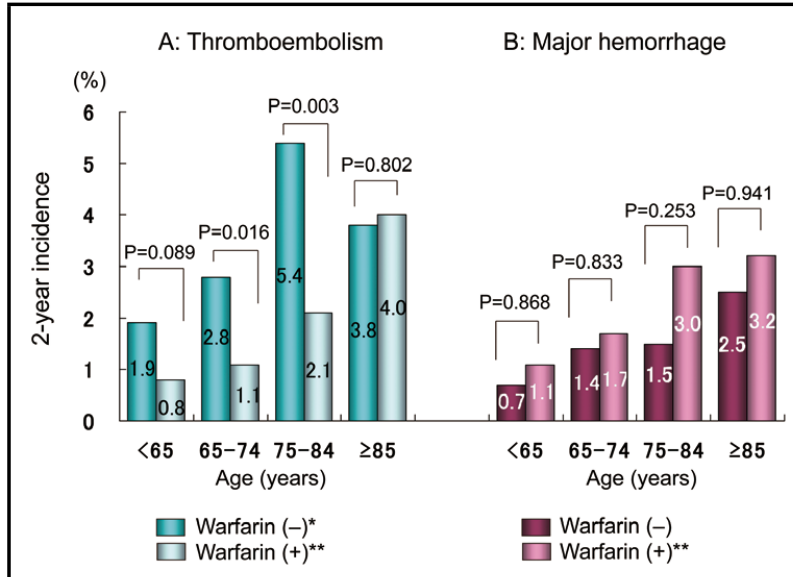

Figure 2. The 2-year incidence of thromboembolism $(\mathbf{A})$ and major hemorrhage (B) by age group in the J-RHYTHM Registry. P-values: comparison between patients with and without warfarin in each age group. ${ }^{*} \mathrm{P}=0.027$ for trend, ${ }^{* *} \mathrm{P}<0.001$ for trend. (Cited with permission from Kodani $\mathrm{E}$, et al. ${ }^{10}$ )

aged $\geq 75$ years was significantly higher compared with that in those aged $<65$ years in the study by Yu et al ${ }^{2}$ (Figure 1B). Age is also a risk factor for thromboembolic and hemorrhagic complications. The risk of thromboembolism and major hemorrhage increased linearly with age in the J-RHYTHM Registry, which was a prospective observational study and followed 7,406 Japanese non-valvular AF patients, including 6,404 treated with warfarin for 2 years ${ }^{10}$ (Figure 2). However, warfarin could have beneficial effects, even in very old patients, if the international normalized ratio of prothrombin time is maintained between 1.6 and 2.6.10

Another important issue to consider is whether concomitant antiplatelet therapy affects the prevalence of genitourinary tract bleeding. Antiplatelet use generally increases the incidence of hemorrhagic complications. However, antiplatelet use did not affect the main results after propensity score matching in the study by $\mathrm{Yu}$ et al, despite the frequency of aspirin use being significantly different between patients with and without OAT. ${ }^{2}$

\section{Expectation of Future Studies}

Although the study by $\mathrm{Yu}$ et al only focused on hematuria and genitourinary complications, ${ }^{2}$ it would be interesting to complete the same analyses with regard to gastrointestinal bleeding in the same population. In addition, warfarin was the sole anticoagulant in that study. ${ }^{2}$ The influence of non-vitamin $\mathrm{K}$ antagonist oral anticoagulants (NOACs or direct oral anticoagulants [DOACs]) on genitourinary bleeding may be different from that of warfarin as for gastrointestinal bleeding. Additional studies using NOACs are expected in the future. Thus far, in recent reports of the J-RHYTHM Registry 2 from Japan, which was an extended study of the J-RHYTHM Registry for 3 years, ${ }^{\mathbf{1 1}}$ and an observational cohort study using Danish nationwide data- bases with more than 60,000 patients, ${ }^{\mathbf{1 2}}$ the risk of major hemorrhage has been significantly lower in patients receiving NOACs compared with that in those receiving warfarin.

\section{Concluding Remarks}

Anticoagulation therapy is an indispensable clinical intervention for the prevention of cardiogenic thromboembolism in patients with AF. Concurrently, it can be said that anticoagulation therapy plays an important role in the early detection of genitourinary cancer, especially bladder cancer, in patients with AF. Because the early detection of occult malignancy is extremely important for all patients to obtain a true net clinical outcome, meticulous evaluation of the cause of hematuria is necessary and important when hematuria is found during anticoagulation therapy.

\section{Disclosures}

The author has no conflicts of interest to disclose.

\section{References}

1. Singer DE, Chang Y, Fang MC, Borowsky LH, Pomernacki NK, Udaltsova N, et al. The net clinical benefit of warfarin anticoagulation in atrial fibrillation. Ann Intern Med 2009; 151: 297-305.

2. Yu HT, Kim TH, Uhm JS, Kim JY, Pak HN, Lee MH, et al. Clinical significance of hematuria in atrial fibrillation with oral anticoagulation therapy. Circ J 2017; 81: 158-164.

3. Lewis JD, Ferrara A, Peng T, Hedderson M, Bilker WB, Quesenberry CP Jr, et al. Risk of bladder cancer among diabetic patients treated with pioglitazone: Interim report of a longitudinal cohort study. Diabetes Care 2011; 34: 916-922.

4. Levin D, Bell S, Sund R, Hartikainen SA, Tuomilehto J, Pukkala E, et al. Pioglitazone and bladder cancer risk: A multipopulation pooled, cumulative exposure analysis. Diabetologia 2015; 58: $493-504$.

5. Lewis JD, Habel LA, Quesenberry CP, Strom BL, Peng T, Hedderson MM, et al. Pioglitazone use and risk of bladder cancer and other common cancers in persons with diabetes. JAMA 2015; 314: 265-277.

6. Dormandy JA, Charbonnel B, Eckland DJ, Erdmann E, MassiBenedetti M, Moules IK, et al. Secondary prevention of macrovascular events in patients with type 2 diabetes in the PROactive Study (PROspective pioglitAzone Clinical Trial In macroVascular Events): A randomised controlled trial. Lancet 2005; 366: $1279-1289$.

7. Blumentals WA, Foulis PR, Schwartz SW, Mason TJ. Does warfarin therapy influence the risk of bladder cancer? Thromb Haemost 2004; 91: 801-805.

8. Pengo V, Noventa F, Denas G, Pengo MF, Gallo U, Grion AM, et al. Long-term use of vitamin $\mathrm{K}$ antagonists and incidence of cancer: A population-based study. Blood 2011; 117: 1707-1709.

9. Tagalakis V, Tamim H, Blostein M, Collet JP, Hanley JA, Kahn SR. Use of warfarin and risk of urogenital cancer: A populationbased, nested case-control study. Lancet Oncol 2007; 8: 395-402.

10. Kodani E, Atarashi H, Inoue H, Okumura K, Yamashita T, Origasa $\mathrm{H}$. Use of warfarin in elderly patients with non-valvular atrial fibrillation: Subanalysis of the J-RHYTHM Registry. Circ J 2015; 79: 2345-2352.

11. Kodani E, Atarashi H, Inoue H, Okumura K, Yamashita T, Origasa $\mathrm{H}$. Beneficial effect of non-vitamin $\mathrm{K}$ antagonist oral anticoagulants in patients with nonvalvular atrial fibrillation: Results of the J-RHYTHM Registry 2. Circ J 2016; 80: 843-851.

12. Larsen TB, Skjoth F, Nielsen PB, Kjaeldgaard JN, Lip GY. Comparative effectiveness and safety of non-vitamin $\mathrm{K}$ antagonist oral anticoagulants and warfarin in patients with atrial fibrillation: Propensity weighted nationwide cohort study. BMJ 2016; 353: $\mathrm{i} 3189$. 